\title{
Patrimonio disperso de la Universidad de Salamanca: dos lienzos de Claudio Coello y el calvario del primitivo retablo
}

\author{
Manuel PÉREZ HERNÁNDEZ \\ Universidad de Salamanca
}

\begin{abstract}
RESUMEN. El hallazgo en el Archivo de la Universidad de Salamanca de una serie de documentos relacionados con su capilla de San Jerónimo nos ha permitido completar la información que ya teníamos sobre las reformas llevadas a cabo en ese lugar a mediados del siglo XVIII, momento en el que fue erigido el retablo de mármoles y jaspes de Simón Gabilán Tomé. También hemos podido confirmar la pertenencia a la capilla universitaria de los dos lienzos de Claudio Coello que en la actualidad se encuentran en la Capilla de la Venerable Orden Tercera del Carmen de Salamanca, y que el calvario del retablo mayor de la iglesia de San Benito de la misma ciudad no es otro que el calvario en el que remataba el retablo realizado a principios del siglo XVI por Felipe Bigarny y Juan de Flandes, entre otros, para la capilla del Estudio, y que hasta el momento se daba por desaparecido.

Palabras clave: Universidad de Salamanca, Capilla de San Jerónimo, Retablo, Gil de Ronza, Claudio Coello, Simón Gabilán Tomé.

ABSTRACT. The finding, in the Archive of the University of Salamanca, of series of documents related to the chapel of San Jerónimo, has allowed us to complete the information we already had about the reforms carried out in that place in the mid eighteenth century, when the marble and jasper altar of Simón Gabilán Tomé was built. We could also confirm that the two paintings of Claudio Coello, currently found in the Chapel of Venerable Third Order of Carmen of Salamanca, belong to the University Chapel and also the calvary of the main altarpiece of San Benito is the same as the calvary that topped the altarpiece created in the early sixteenth century by Felipe Bigarny and Juan de Flandes, among others, for the Chapel of the Studio, and this one nowadays was considered lost.

Key words: University of Salamanca, Chapel of San Jerónimo, Altarpiece, Gil de Ronza, Claudio Coello, Simón Gabilán Tomé.
\end{abstract}

En enero de 1914, de eso hace prácticamente un siglo, D. Manuel GómezMoreno publicaba en el Boletín de la Sociedad Castellana de Excursiones un documentado artículo, titulado "La capilla de la Universidad de Salamanca"1, en el que

*Quede constancia del agradecimiento a mi compañero del Departamento de Historia del Arte-Bellas Artes de la Universidad de Salamanca, Eduardo Azofra, experto conocedor del patrimonio universitario ilustraba a través de las actas de los libros de claustros la reforma llevada a cabo en el

salmantino, por los comentarios y cambios de impresiones habidos durante la redacción de este trabajo. También a D. Vicente Sierra Puparelli, archivo fotográfico vivo de la ciudad de Salamanca, suyas son las imágenes que ilustran este artículo.

${ }^{1}$ M. GOMEZ-MORENO, «La capilla de la Universidad de Salamanca», Boletín de la Sociedad Castellana de Excursiones, 1913-1914, pp. 321-324. 
siglo XVI en ese espacio del edificio de las Escuelas Mayores², que para él, y desde entonces para la mayor parte de cuantos han escrito sobre este edificio, era la segunda capilla del Estudio salmantino ${ }^{3}$.

La transformación de ese espacio tuvo en el nuevo retablo a su principal protagonista, hasta el punto de que fueron sus grandes dimensiones las que determinaron que a principios de ese siglo (1506) quedara unificado en altura un volumen hasta entonces dividido, pues no debemos olvidar que por encima del ámbito sagrado se encontraba la librería edificada en la década de los setenta del siglo XV, siendo así que la bóveda que para ella pintó Fernando Gallego pasó a ser el cerramiento de la capilla.

La historia constructiva de ese retablo es bastante conocida, y por el prestigio de los artistas que intervinieron se hace evidente el interés que la Universidad puso en él, confirmándose de este modo lo apuntado por la profesora Lahoz, el protagonismo alcanzado por este tipo de muebles

\footnotetext{
2 Dada la imposibilidad de recoger aquí la abundante bibliografía existente sobre este edificio, únicamente citamos algunos de los trabajos más interesantes. J. Alvarez Villar, La universidad de Salamanca. Arte y tradiciones, Salamanca, 1972. F. PEREDA, La arquitectura elocuente. El edificio de la Universidad de Salamanca bajo el reinado de Carlos V, Madrid, 2000. J. R. NIETO GONZÁLEZ, «Escuelas mayores, menores y hospital del Estudio, siglos XIII-XX», en L. E. RODRÍGUEZ-SAN PEDRO BEZARES (coord.), Historia de la Universidad de Salamanca II. Estructuras y Flujos, Salamanca, 2003, pp. 375-456. En relación con sus bienes muebles, J. R. NiETO GONZÁLEZ y E. AZOFRA AGUSTíN, Inventario de bienes muebles de la Universidad de Salamanca, Salamanca, 2002.

${ }^{3}$ De esa tesis disiente Lucía Lahoz, para quien la capilla siempre estuvo en el mismo lugar, y el espacio habitualmente denominado zaguán es sencillamente eso, un lugar de acceso al edificio desde la puerta de las Cadenas. L. LAHOZ, "Imagen visual de la Universidad de Salamanca", en L. E. RODRÍGUEZ-SAN PEDRO BeZAreS y J. L. POlo Rodríguez (coords.), Historia de la Universidad de Salamanca, vol. IV, Vestigios y entramados, Salamanca, 2009, pp. 287-325.
}

litúrgicos a fines de la Edad Media a la hora de remozar ámbitos necesitados de una renovación ${ }^{4}$. No obstante aún quedan incógnitas por desvelar, es el caso del programa iconográfico que contenía, el de sus ideólogos, aunque algunos nombres se han propuesto $^{5}$, e incluso la posibilidad de que el proyecto primitivo se hubiera visto modificado en el transcurso de su ejecución, posibilidad planteada por Pilar Silva en un estudio dedicado a Juan de Flandes ${ }^{6}$, y que retoma la mencionada Lucía Lahoz.

La nómina de artistas vinculados a este proyecto también resulta suficientemente conocida, corriendo a cargo de Felipe Bigarny y Antón de Lorena la escultura, y a Juan de Flandes, Juan de Iprés y Juan de Borgoña el dorado y la pintura, tanto de las historias como de las imágenes de bulto. A todos ellos cabe añadir el nombre de Gil de Ronza, quien ya había trabajado para la propia universidad labrando una imagen de bulto de San Nicolás ${ }^{7}$, y que bien pudo tallar el calvario en el que remataba todo el conjunto.

Con lo expuesto hasta ahora no hemos pretendido más que hacer un relato, necesariamente breve, en la bibliografía citada lo encontrará el lector interesado de una manera más desarrollada, del impacto que esta obra tuvo en la remodelación de la capilla universitaria a principios del siglo XVI, ámbito que estuvo llamado a presidir durante los posteriores dos siglos y medio,

\footnotetext{
${ }^{4}$ L. LAHOZ, «La imagen visual...», p. 305

${ }^{5}$ Felipe Pereda asegura que bien pudiera deberse a los dominicos fray Alonso de Peñafiel y Pedro León, catedráticos de teología, nómina a la que Lucía Lahoz propone sumar el de Juan de Castro. F. PEREDA, La arquitectura elocuente..., p. 56; L. LAHOZ, «La imagen visual...», p. 305.

${ }^{6}$ P. SiLva MAROTO, Juan de Flandes, Salamanca, 2006.

${ }^{7}$ M. GÓMEZ-MORENO, «La capilla...», p. 327.
} 
exactamente hasta que en 1761 se iniciaron las obras de remodelación de ese espacio ${ }^{8}$.

Debemos suponer, no obstante, que la imagen que en ese momento ofrecía la capilla universitaria ya diferiría bastante de la que tenía en el Quinientos, y se aproximaría, si se me permite la expresión, a un palimpsesto artístico en el que convivían, seguramente no sin conflicto, elementos que respondían a concepciones estéticas e ideológicas diferentes. Que la capilla universitaria, y en particular la zona del altar, había ido transformándose para adecuarse a la sensibilidad religiosa de cada momento lo confirman algunas intervenciones llevadas a cabo en el transcurso del siglo XVII. Es el caso de la ejecutada a finales de la década de los veinte, cuando la necesidad de exponer dignamente la colección de reliquias que el obispo Sancho Dávila había regalado unos años antes a la capilla universitaria, y que inicialmente se pensaron colocar en la sacristía, se resolvió finalmente con un retablo que, a modo de lipsanoteca, se instaló en el lado del evangelio, una actuación que debemos enmarcar en el desarrollo del culto a las reliquias promovido por el Concilio de Trento 9 . Otro tanto sucedió a fines de la misma centuria, cuando con motivo de la canonización de San Juan de Sahagún (1691) se erigieron dos altares para alojar las imágenes de Santo Tomás de Villanueva y del propio San Juan de Sahagún, dos lienzos cuyos marcos son ejemplo de ese lenguaje exuberante y recargado característico del pleno barroco.

\footnotetext{
8 Sobre esta intervención puede consultarse: A. Rodríguez G. DE CEBAllos y J. R., NiETO GONZÁlez, "Aportaciones a Simón Gabilán Tomé», Archivo Español de Arte, 1981, pp. 29-60. J. R. NIETO GONZÁLEZ, «Escuelas Mayores...», especialmente pp. 412-415.

${ }^{9}$ Sobre esta cuestión, y la mentalidad del donante, J. SANZ HERMIDA, «Un coleccionista de reliquias: don Sancho Dávila y el Estudio Salmantino». Vía Spiritus, 2001, pp. 59-93.
}

En conclusión, con una intervención como la llevada a cabo en la capilla universitaria en los años centrales del siglo XVIII seguramente no solo se perseguía adecuar el lugar a los gustos artísticos del momento, emulaba así la Universidad lo que se estaba haciendo en otros edificios emblemáticos de la ciudad del Tormes, también se buscaba un criterio de unidad entre todos los elementos que la conforman (arquitectura y exorno), e igualmente la adaptación del espacio a los nuevos usos litúrgicos que potenciaban el altar y el retablo como lugar de exaltación eucarística, de ahí esa elección, como en su momento expuso Rodríguez G. de Ceballos, por un retablo a medio camino entre el retablo eucarístico y el retablo camarín ${ }^{10}$.

Con frecuencia se ha señalado que el motivo principal de todas las reformas llevadas a cabo en este lugar desde mediado el siglo XVIII, y especialmente la sustitución del viejo retablo por el de mármoles y jaspes diseñado por Gabilán Tomé, fue la proclamación de la Inmaculada Concepción de la Virgen como patrona de la Universidad de Salamanca ${ }^{11}$, y el deseo de colocar su imagen de forma permanente en el retablo, decisión adoptada en el claustro pleno celebrado el 19 de junio de $1761^{12}$. Existe, no obstante, un desajuste cronológico en el curso de los acontecimientos que permite, cuando menos, poner en cuestión esa afirmación. Cuando se aprueban las trazas del retablo, hecho que sucede en el claustro de

${ }^{10}$ A. Rodriguez G. DE Ceballos, «El retablo barroco en Salamanca: materiales, formas, tipologías», Imafronte, 1987-1989, pp. 225-258

${ }^{11}$ Así lo manifiestan, entre otros, A. RODRÍGUEZ G. de Ceballos y J. R. Nieto GonzÁlez, «Aportaciones...», p. 209; y J. R. NIETO GONZÁLEZ, «Escuelas Mayores...», p. 412.

${ }^{12}$ Archivo de la Universidad de Salamanca (en adelante AUSA), Libro de Actas de Claustro y Juntas de la Universidad (1760-1762), sig. 229, fol. 39ro y sgts. 
Primicerio celebrado el 29 de abril de $1760^{13}$, la Inmaculada aún no había sido declarada patrona de la Universidad, y desconocemos hasta qué punto ya habían sido seleccionadas las imágenes que en él se iban a colocar, pues no debemos olvidar que los lienzos ubicados en el cuerpo inferior, como documentó el profesor Álvarez Villar, no se recibieron hasta cuatro años después ${ }^{14}$.

En cambio, considero que no se ha prestado la atención debida a un proyecto anterior en el tiempo, y ya materializado en el momento en el que suceden esos acontecimientos, que no solo pudo influir en esa decisión sino también condicionar la estructura de la obra que se pensaba realizar. Me estoy refiriendo al tabernáculo de plata labrado por Manuel García Crespo, una pieza destinada, desde el principio, a ocupar el camarín del nuevo retablo, y que se ocultaba tras el lienzo pintado por el milanés Francesco Caccianiga que representa el juramento hecho por los claustrales salmantinos en 1618 de defender el dogma de la Inmaculada Concepción, tela que era retirada, dejando ver la obra argéntea, con motivo de festividades como el Jueves Santo y Corpus Christi ${ }^{15}$.

13 AUSA. Actas de Sesiones de Claustros de Primicerio. 1752-1781. Sig. 834, fols. $25 \mathrm{r}^{\mathrm{o}} \mathrm{y}$ sgts. En esa sesión se presentaron tres propuestas, dos firmadas por Simón Gabilán Tomé y la tercera por Miguel Martínez. Recabada la opinión de Juan de Sagarbinaga, este consideró como más adecuada una de las que iba firmada por el primero de los arquitectos mencionados.

14 J. Álvarez VILlar, La Universidad de Salamanca..., p. 80 .

${ }^{15}$ A. RODRIGUEZ G. DE CEBALLOS, «Los plateros del siglo XVIII Manuel y Luís García Crespo y su obra en Tierras de León», Tierras de León, 1979, pp. 60-70. M. PÉREZ HERNÁNDEZ, «Sobre la interdisciplinariedad de las artes: Manuel García Crespo y el Barroco salmantino», en J. RIVAS CARMONA (coord.), Estudios de Platería. San Eloy 2007. Murcia, 2007, pp. 271-297. Sobre la
El proyecto de hacer un tabernáculo de plata fue planteado por vez primera en la sesión celebrada por el claustro de Primicerio el 10 de junio de 1743. En ella, Miguel Joly, primicerio ese año, afirma que con su propuesta está recogiendo el sentir de sus predecesores: ... haviendo oido a señores primicerios sus antecesores el deseo que havian tenido de que se hiziese para la Real Capilla de San Gerónimo un tabernáculo dezente para poner a Su Majestad... ${ }^{16}$. La obra tendría una altura de dos varas y dos tercias (aproximadamente $223 \mathrm{~cm}$.) y un peso de 1300 onzas de plata (aproximadamente $36,8 \mathrm{~kg}$.), cifrándose el coste total del proyecto (valor de la plata, hechura, madera y oro para dorar algunas partes) en 43565 reales, cifra que podría reducirse fundiendo algunas piezas inservibles pertenecientes a la propia capilla. El 24 de julio de ese mismo año los comisarios nombrados a tal efecto presentaron a los miembros del claustro una serie de trazas, con su coste, y aunque no se menciona a los autores de los bocetos sí se dice que Francisco Villarroel, que aseguraba haber sido el platero de la Universidad

desaparición de esta obra durante la Guerra de la Independencia, M. PÉREZ HERNÁNDEZ, «Salamanca y la Guerra: Repercusiones en la platería», REVSA Salamanca Revista de Estudios, 1997, pp. 61-84.

${ }^{16}$ AUSA. Actas de Sesiones de Claustros de Primicerio. $1653-1752$. Sig. 833 , fols. $274 \mathrm{r}^{\mathrm{o}}$ y sgts. De lo anterior se deduce que dicha cuestión llevaba latente algunos años, siendo ahora cuando se decide abordar. Tal vez una empresa de este tipo no deba desvincularse del proyecto de tabernáculo que apenas una década antes Alberto de Churriguera y José de Larra habían realizado para la catedral, inaugurado en el mes de agosto de 1733, aunque no debemos obviar que difieren tanto en el tamaño como en el lugar en el que serían colocados. Sobre esta obra, que nació con vocación de permanencia, pero que adquirió la condición de efímera por su corta vida, en 1745 el cabildo catedralicio acuerda su demolición, puede consultarse: $\mathrm{M}$. CASAS HERNÁNDEZ, Un proyecto de los Churriguera: el tabernáculo y el coro de la Catedral Nueva de Salamanca. Universidad de Salamanca. Trabajo de Grado inédito, 2008. 
desde hacía tres décadas, se ofrecía a ejecutar el modelo que saliera elegido.

Este primer intento quedó, una vez más, en el olvido, debiendo esperar trece años para verlo realizado, sin que sepamos el motivo de tanta demora. En el claustro de Primicerio celebrado el 13 de abril de 1756 se retoma el proyecto, aprobando los asistentes su ejecución, no obstante hubo algún miembro del claustro, como el Dr. D. Tomás Bajo, que, aún mostrando su acuerdo con la decisión adoptada, opinaba si no se havia de empezar primero por otro camino, como era el que los altares que estan a los lados del altar mayor se idease de ponerlos de modo que mirasen a la puerta de la capilla... ${ }^{17}$. Aunque no de una manera explícita, parece que la imagen que ofrecía el altar no era la más adecuada para alojar la obra que se proponían hacer, máxime teniendo en cuenta que debería estar colocada de manera permanente, pues como manifestaron algunos claustrales, por su tamaño y delicadeza no convenía moverla ni desmontarla.

Una vez tomada la decisión de hacer un nuevo retablo, la ubicación del tabernáculo y el acceso al camarín donde sería colocado fue objeto de un informe elaborado por los arquitectos Andrés García de Quiñones, Simón Gabilán Tomé y Juan de Sagarbinaga, leído en el claustro de Primicerio celebrado el 12 de julio de 1763, en él planteaban un acceso al mismo desde la sacristía ${ }^{18}$, facilitando de este modo la colo-

17 AUSA. Actas de Sesiones de Claustros de Primicerio. 1752-1781. Sig. 834, fols. $8 \mathrm{r}^{\mathrm{o}} \mathrm{y}$ sgts.

18 AUSA. Actas de Sesiones de Claustros de Primicerio. 1752-1781. Sig. 834, fols. $30 v^{\mathrm{o}}$ y sgts.. Fue en esa misma sesión donde también se tomó la determinación de construir una nueva bóveda, curiosa y adornada, pues el cielo que tenia la capilla era muy antiguo, y las figuras que en el estan gravadas no estan con formalidad pues le faltaban muchas..., una decisión que no fue unánime, pues entre algunos de los asistentes se argumentó que no combenia hacer ninguna mudanza en el zielo de dicha capilla, pues era obra excelente y magnifica.... cación del Santísimo. No obstante lo anterior, el proyecto no fue ejecutado hasta pasado algún tiempo, concretamente en la sesión celebrada por ese mismo claustro el 30 de julio de 1791 se da lectura a un informe redactado por Jerónimo García de Quiñones en el que se comprometía a hacer una escalera desde la sacristía al camarín, evitando así la irreverencia que causaba que el oficiante tuviera que subirse al ara para colocar el Santísimo para su exposición ${ }^{19}$.

El proceso de realización del retablo no estuvo exento de polémica, obligando incluso a que otros arquitectos tuvieran que informar sobre lo que se estaba realizando. Especialmente conflictivo fue el año 1765, cuando Gabilán Tomé fue despedido como maestro de la obra, por considerar el comisario de la misma, José Carrio, que para su finalización bastaba con la dirección del aparejador Nicolás Rodríguez. Esa circunstancia fue aprovechada por el maestro toresano para presentar un informe en el que denunciaba una serie de errores que se estaban cometiendo en la talla de algunos elementos, derivados principalmente de la perspectiva oblicua empleada en su arquitectura, al tiempo que solicitaba su reincorporación a la dirección de la obra. Demanda también a la Universidad que pida una evaluación de lo realizado a Francisco Moradillo, arquitecto que el cabildo salmantino estaba esperando para que informara de los problemas detectados en la torre de la catedral tras el terremoto de Lisboa $(1755)^{20}$. El

${ }^{19}$ AUSA. Actas de Sesiones de Claustros de Primicerio. 1781-1834. Sig. 835 , fols. $74 \mathrm{v}^{\mathrm{o}} \mathrm{y}$ sgts.

${ }^{20}$ Dicho informe fue leído en el claustro de Primicerio celebrado el 8 de julio de 1765 , en él se atribuye a Nicolás Rodríguez la responsabilidad de los defectos. Tras un largo debate los claustrales deciden recabar la opinión de otros maestros, concretamente de Miguel Martínez y Antonio Montero. AUSA. Actas de Sesiones de Claustros de Primicerio. 1752-1781. Sig. 834, fols. $41 v^{\mathbf{o}}$ y sgts. No fue éste el único informe que el arquitecto madrileño hizo durante su estancia en 
informe redactado por el arquitecto madrileño está fechado el 3 de septiembre de 1765 , y aunque reconoce algunos errores considera que al final podrá quedar bien: ...de todos modos no sera la obra la mejor entre las que oy vemos de este material; pero tampoco dejara de parecer bien y lucir el todo, teniendola por muy decente aun los profesores del arte..., acusando como principal defecto la falta de proporción entre los cuerpos: ...Pero como en esta clase de obras si desde el principio no se camina al fin propuesto por medio de su planta, proporcionandola en sus modulos con respecto a uno, dos o mas cuerpos (elegidos antes) parece imposibe su logro aunque el arquitecto haga prodigios... ${ }^{21}$.

Como ya hemos señalado, el conjunto de reformas llevadas a cabo en ese tiempo tuvo como consecuencias inmediatas la adecuación estética del ámbito religioso de las Escuelas Mayores al gusto de los nuevos tiempos, y su adaptación a la sensibilidad religiosa del momento, potenciando el protagonismo del altar y la exaltación del Sacramento a través del tabernáculo de plata que se colocó en el camarín del retablo. No obstante también provocó daños colaterales, siendo los principales la desaparición del viejo retablo de principios del siglo XVI, el ocultamiento de la que hasta entonces había sido bóveda de la capilla universitaria, y el desplazamiento de otros adornos de la capilla del lugar para el que fueron creados. Relatar el destino de algunas de esas piezas que lucía la capilla universitaria antes de su renovación, y de algunos ele-

Salamanca, también emitió otro sobre la intervención que se estaba llevando a cabo en la iglesia de San Blas. N. RupÉrez AlmajANO, «Las intervenciones de Juan de Sagarvinaga, Nicolás Rodríguez y Jerónimo García de Quiñones en la iglesia de San Blas (Salamanca)», en Boletín del Seminario de Estudios de Arte y Arqueología, 1992, pp. 469-480.

${ }^{21}$ AUSA. Actas de Sesiones de Claustros de Primicerio. $1752-1781$. Sig. 834 , fols. $48 \mathrm{v}^{\mathrm{o}}$ y sgts. mentos del viejo mueble litúrgico será lo que nos ocupe a partir de este momento.

Hasta ahora las únicas obras conocidas que se habían conservado del retablo del siglo XVI eran los dos bustos de Santa Apolonia y Santa María Magdalena pintados por Juan de Flandes, que formaban parte de los diez que iban en la predela, y las seis tallas que vio Gómez -Moreno: San Jerónimo, San Juan Bautista, la Inmaculada, Santa Bárbara, San Agustín y San Gregorio, las dos primeras se encontraban en el momento en que redactaba su artículo sobre la capilla universitaria el historiador granadino en la sacristía de la capilla del Estudio, y las cuatro restantes paraban en lo que había sido capilla del Hospital de Santo Tomás, donde las halló el entonces rector D. Miguel de Unamuno ${ }^{22}$.

Hoy disponemos de una información más precisa de lo que sucedió con algunos elementos del viejo retablo, y ya adelantamos que se conservan más piezas de las que hasta ahora conocíamos. Entre los asuntos del orden del día del claustro de Primicerio celebrado el 3 de noviembre de 1772 se incluía uno encaminado a determinar qué hacer, una vez finalizadas las obras de la capilla, con algunos cuadros, esculturas de bulto, ornamentos y alhajas sobrantes, siendo la decisión tomada por sus miembros que se aprovechase lo que sirviera, y lo que no se dejara para el servicio de la capilla del Hospital ${ }^{23}$, donde por otra parte muchos de ellos permanecían desde el inicio de las obras (no debemos olvidar que

\footnotetext{
22 Referencias a estas obras, con bibliografía sobre cada una de ellas, pueden verse en: J. R. NIETO GONZÁlEZ y E. AZOFRA AgUSTín, Inventario artístico.... A ellas hay que sumar la imagen de Santa Catalina de Alejandría que se conserva en el Museo de San Gregorio de Valladolid.

${ }^{23}$ Sobre esta institución, y el edificio donde tenía su sede, vid. T. SANTANDER, El Hospital del Estudio (1413-1810), Salamanca, 1993, pp. 39-43.
} 
la capilla del Hospital sustituyó en los actos religiosos a la de San Jerónimo mientras duró la reforma), o se repartiese entre algunas iglesias pobres en las que la Universidad disfrutase de rentas. Contra este acuerdo únicamente se alzó la voz discrepante de fray José de Alba, quien manifestó que las pinturas que tenia el retablo son excelentes, y ninguna se enagene de la Universidad ${ }^{24}$.

Se ha conservado, además, otro relato más preciso del destino que siguieron algunas piezas. Se trata de un addenda al acta de la sesión celebrada por ese mismo claustro de Primicerio el 11 de noviembre de 1773, que lleva por título Sobre ynventario de alajas sobrantes en la capilla de San Geronimo y su distribucion ${ }^{25}$. Sabemos por ese documento que al Hospital de Santo Tomás, para el servicio de su capilla, la de su enfermería e iglesia de San Nicolás, además de algunos ornamentos litúrgicos, se le entregaron diferentes santos de madera que sirvieron al retablo que se desmonto en la capilla de San Geronimo, como son un Santisimo Cristo, su Santísima Madre y San Juan al pie (obviamente se trata del calvario que iba en el ático del desmembrado retablo), dos cuadros de San Juan de Sahagun y Santo Tomas de Villanueba, nueve santos de bulto y diversa magnitud ... Otros ornamentos se distribuyeron entre la iglesia de Santiago, extramuros de la ciudad, y las de Carbajosa, Vecinos, Tornadizo, Navagallega y Llen, al templo de este último lugar se entregaron un sagrario y tres santos de bulto, sin que se indique su identidad.

Antes de proseguir con otras cuestiones, merece la pena que nos detengamos un momento sobre los dos cuadros que según el citado documento estaban deposi-

\footnotetext{
${ }^{24}$ AUSA. Actas de Sesiones de Claustros de Primicerio. $1752-1781$. Sig. 834 , fols. $112 \mathrm{v}^{\mathrm{o}} \mathrm{y}$ sgts.

${ }^{25}$ AUSA. Actas de Sesiones de Claustros de Primicerio. 1752-1781. Sig. 834 , fols. $120 \mathrm{r}^{\mathrm{o}}{ }^{\mathrm{y}}$ sgts.
}

tados en la capilla del Hospital, uno dedicado a San Juan de Sahagún y otro a Santo Tomás de Villanueva, y que en nuestra opinión no son otros que de los dos lienzos de Claudio Coello, fechados en 1691, que actualmente se conservan en la capilla de la Venerable Orden Tercera del Carmen, más conocida como el Carmen de Abajo (Fig. $1)^{26}$.

La primera noticia sobre estas pinturas en su ubicación actual fue proporcionada por Camón Aznar en 1932, que además de ensalzar su calidad las considera obra indudable de Claudio Coello ${ }^{27}$. Unos años después, en 1953, Manuel Ibáñez publica un artículo en la revista Archivo Español de Arte en el que además de confirmar la autoría, pues pudo ver la firma del pintor madrileño, asegura que ambos lienzos habían pertenecido al extinto convento de San Agustín, del que habrían pasado en 1809 a la capilla del Estudio, lugar donde aún permanecían en 1849. Un año después la Tercera Orden se los pidió a la Universidad para decorar su capilla, a lo que ésta accedió $^{28}$. Como únicos argumentos para sustentar su teoría aportó: que Coello había trabajado para la comunidad Agustina de Zaragoza, y que unos años antes había pintado el lienzo del Martirio de San Esteban para el retablo mayor de la iglesia del convento de los dominicos de Salamanca, una hipótesis que ha sido unánimemente aceptada por toda la historiografía posterior ${ }^{29}$.

\footnotetext{
${ }^{26}$ Para una aproximación a la obra de este pintor: E. J. SUlLivan, Claudio Coello y la pintura barroca madrileña. MADRID, 1989; A. E. PÉREZ SÁNCHEZ, «En torno a Claudio Coello», en Archivo Español de Arte, 1990, pp. 129-156.

27 J. CAMÓn AZnAR, Guía de Salamanca. Madrid, 1932, p. 97.

${ }^{28}$ M. IBÁÑEZ, «Dos cuadros firmados por Claudio Coello», Archivo Español de Arte, 1953, pp. 129-132.

${ }^{29}$ B. VElASCO BAYÓN, Colegio mayor universitario de Carmelitas de Salamanca. Salamanca, 1978, p. 109. E.
} 
Tras la información proporcionada por los nuevos datos no tenemos ninguna duda de que ambos lienzos nunca pertenecieron al convento de San Agustín, sino que siempre estuvieron en la capilla de San Jerónimo, aunque es verdad que fueron sufragados por la comunidad Agustina de Salamanca. Confirman lo que decimos las actas de diversos claustros celebrados en el transcurso de los años 1690-1691, fechas en las que se produjo la canonización del patrón de la ciudad del Tormes ${ }^{30}$.

La primera noticia de la canonización del santo leonés llega a la Universidad en el claustro pleno celebrado el 20 de noviembre del año 1690, en él se da lectura a una carta remitida por el cardenal Aguirre informando del hecho, tomando los miembros del claustro la decisión de celebrar una fiesta cuando la notificación fuera oficial, circunstancia que se produjo el 22 de diciembre de ese mismo año ${ }^{31}$. Mayor interés, para la

MONTANER LÓPEZ, La pintura barroca en Salamanca, Salamanca, 1987, pp. 175-176. E. MONTANER LÓPEZ, Pintura barroca en Salamanca. Escuelas españolas. Salamanca, 1987, pp. 48-49. M. PÉREZ HERNÁNDEZ, «Lienzos de San Juan de Sahagún y Santo Tomás de Villanueva (Claudio Coello)», en J. M. MARTíNEZ FRÍAS, M. PÉREZ HeRnÁNDEZ, y L. LAHOZ, El arte barroco en Salamanca, Salamanca, 2008, pp. 126-127.

${ }^{30}$ Beatificado por Clemente VIII el 23 de junio de 1601, fue canonizado el 16 de octubre de 1690, durante el pontificado de Alejandro VIII, y promulgada la bula de su canonización el 15 de junio del año siguiente, siendo Papa Inocencio XII.

${ }^{31}$ AUSA. Libro de Actas de Claustro y Juntas de la Universidad (1690-1691), sig. 160, fols. $2 \mathrm{v}^{\mathrm{o}}$ y $8 \mathrm{v}^{\mathrm{o}}$, respectivamente. En realidad las primeras noticias en las actas de claustro sobre el proceso de canonización de San Juan de Sahagún son anteriores, pues en la sesión celebrada el 17 de noviembre de 1689 se nombra una comisión, formada por los Dres. Pedro Abarca e Íñigo Royo, encargada de redactar cartas favorables a dicha canonización (AUSA. Libro de Actas de Claustro y Juntas de la Universidad (1689-1690), sig. 159, fol. 2 $\mathrm{v}^{\mathrm{o}}$ ). Sobre los actos festivos organizados para celebrar el acontecimiento puede consultarse: F. J. CAMPOS Y FERNÁNDEZ DE SEVILLA, «Fiestas celebradas en Salamanca con motivo de la canonización de su patrón San cuestión que nos ocupa, tiene lo tratado en el claustro pleno del 11 de enero de 1691, en él se escucha una proposición de fray Manuel Duque, de la orden de San Agustín, en la que en su nombre, y en el de su comunidad, pide a la Universidad se de culto y veneración a los santos agustinos Tomás de Villanueva y Juan de Sahagún, ... poniendoles dos altares permanentes para siempre jamas en su capilla real de San Gerónimo..., añadiendo que su coste sería íntegramente sufragado por el convento donde ambos profesaron $^{32}$. La propuesta fue unánimemente aceptada, únicamente se hicieron algunas observaciones sobre el lugar donde se ubicarían, y advertencias para que se pusiera cuidado en que no afectaran a la estabilidad de las paredes maestras de la capilla, para lo cual se consultaría con maestros alarifes. Seis meses más tarde, en la sesión celebrada por el claustro universitario el 7 de junio de 1691, el citado Manuel Duque, junto a Pedro Terán, de la misma Orden, después de agradecer al Estudio la licencia para construir los citados altares, comunican que los cuadros estavan esperando por instantes y los marcos estavan ia dorados..., y solicitan permiso para poder celebrar una misa con sermón el día que fueran colocados, todo sufragado por los solicitantes, celebración que piden se mantenga en el futuro a su costa ${ }^{33}$.

La presencia permanente de ambos lienzos en los altares elevados al efecto también queda confirmada con otra noticia fechada a mediados del siglo XVIII. En el claustro de Primicerio celebrado el 13 de octubre de 1759, en el que se comunica a los

Juan de Sahagún», en Actas del Simposio, El culto a los santos: cofradías, devoción, fiestas y arte. San Lorenzo del Escorial, 2008, pp. 1054-1078.

${ }^{32}$ AUSA. Libro de Actas de Claustro y Juntas de la Universidad (1690-1691), sig. 160, fols. 10º y sgts.

${ }^{33}$ AUSA. Libro de Actas de Claustro y Juntas de la Universidad (1690-1691), sig. 160, fols. 33ํㅡ y sgts. 
asistentes que Manuel García Crespo había dado por concluido el tabernáculo de plata, y que se debía deliberar sobre la fórmula adecuada para su mejor conservación, ... y de ponerse el altar lo mejor que pudiera ser, para la mayor decencia..., se añade que también convendría adecentar los colaterales donde estan los gloriosos santos de San Juan de Sahagun, y Santo Thomas de Villanueba ${ }^{34}$.

Con todo lo anterior no debe quedar ninguna duda sobre que los dos lienzos procedentes de la capilla de San Jerónimo que a finales del siglo XVIII estaban depositados en la del Hospital de Estudio y los que actualmente se encuentran en la iglesia del Carmen de Abajo son los mismos, y que por lo tanto siempre pertenecieron a la Universidad.

Otra de las obras cuya localización nos han facilitado el hallazgo de los nuevos documentos es el calvario que coronaba el primitivo retablo. Como es sabido, entre los años 1509 y 1510 se trató en diversos claustros la necesidad de tallar esas imágenes, que por otro lado ya estaban contempladas en el contrato que unos años antes el Estudio salmantino había firmado con Felipe Bigarny, e incluso se llegó a designar una comisión para que fuera a ver el crucificado que había en el monasterio de San Leonardo de Alba de Tormes. En opinión de Gómez Moreno el autor de ese calvario pudo ser Gil de Ronza ${ }^{35}$, y ese grupo hasta ahora también se daba por desaparecido.

En 1784 está fechado un documento que, por su indudable interés, transcribimos íntegramente:

Junta de Primicerio febrero $1^{\underline{o}}$ de 1784.

En Salamanca, a primero de febrero de

${ }^{34}$ AUSA. Actas de Sesiones de Claustros de Primicerio. 1752-1781. Sig. 834, fols. $22 r^{\circ}$ y sgts.

${ }^{35}$ M. GÓMEZ-MORENO, “La capilla...”, pp. 326-327. mil setecientos ochenta y quatro, a las diez de la mañana se congregaron en la Sala de Juntas de esta secretaria los señores que constan al margen" en la que se leyo un memorial presentado por don Feliz Martin provisor beneficiado cura parroco de la de San Benito de esta ciudad, en el que suplicaba que con motibo del nuevo tabernáculo hecho en dicha iglesia para su adorno necesitaba de una efigie del Santisimo Christo y Maria de mayor estatura, que los que tenia dicha iglesia eran de menor tamaño que las que la Universidad conserbaba en la capilla del Hospital del Estudio sobrantes del tabernáculo antiguo, por lo que suplicaba a la Junta si lo tenia a bien mandar se le diesen, entregando de dicha iglesia en recompensa quatro cuadros de buena pintura con marcos de ebano y otro christo mas proporcionado para el sitio donde estan colocados el Santisimo Christo y Maria que solicita, y tratado conferido y votado por los señores doctores don Juan Machado, Primicerio del, Antonio Garcia y don Pedro Navarro que son los que componen esta Junta se acordo nemine discrepante el concederle la gracia que solicita, con lo que se concluio esta junta de que doy fe.

Ante mi Diego Garcia de Paredes, Secretario

${ }^{*}$ Los nombres a los que se alude eran los doctores Machado, García y Navarro

La actual iglesia de San Benito fue erigida, entre los años 1506 y 1511, por iniciativa de D. Alonso de Fonseca II, quien había recibido en ella el bautismo, para que sirviera como panteón del linaje Maldonado $^{36}$. A finales del siglo XVIII, en 1783,

-

${ }^{36}$ M. GómeZ-MORENO, Catálogo monumental de España. Provincia de Salamanca. Madrid, 1967, pp. 219-220 (existe una reedición del año 2003, por la que citamos). J. M. MARTíNEZ FrÍAS, «Iglesia de San Benito», en J. M. Martínez FríAs, M. PÉreZ HernándeZ, y L. LAHOZ, El arte gótico en Salamanca, Salamanca, 2005, pp. 98-103. 
aprovechando que la bóveda y arco de la capilla mayor amenazaban ruina se decide fabricar un nuevo retablo, que siguiendo la Real Pragmática de 1777 debería ser de piedra, una obra cuya traza fue realizada por Eustaquio Román, mientras el marmoleado y jaspeado corrió por cuenta de Ramón Micó y José Sánchez Ruano (Figs. 2 y $3)^{37}$.

La bibliografía existente sobre el citado retablo ya se había percatado de que el estilo que presentan las imágenes que componen el calvario no guardan relación con la propuesta estética que ofrecen la estructura y demás figuras del mueble litúrgico en el que se insertan. Una vez más GómezMoreno fue el primero en emitir el juicio que, con mayor o menor fidelidad, ha sido reproducido por la historiografía posterior ${ }^{38}$ : Exceptuase el Calvario, mayor del tamaño natural, que campea en lo alto; pues, aunque repintado en igual forma (se refiere al marmoleado que presentan el resto de imágenes) es labor excelente de principios del siglo XVI y de lo italiano que aquí en Salamanca lucía por entonces, según se dijo a propósito de la Catedral nueva. ${ }^{39}$.

${ }^{37}$ M. J. HeRnÁNDEZ MARTín, Capillas camarín en la Provincia de Salamanca, Salamanca, 1990, pp. 45-47

38 J. CAMÓN AZNAR, Guía de Salamanca, p. 70-71, atribuye su traza a Alejandro Carnicero, y el calvario del remate, que califica de magnífico, a Diego de Siloé, aunque critica el repintado que tienen, monocromía propia del neoclasicismo. La misma valoración estética y atribución de las tallas hace J. M. MARTíNEZ FRÍAS, «Los monumentos religiosos (edad media)», en A. CABO ALONSO y A. ORTEGA CARMONA (coords.), Salamanca. Geografía, Historia, Arte y Cultura. Salamanca, 1986, p. 342. Un juicio similar hace A. RODRIGUEZ G. DE CEBALlos, Guía de Salamanca, León, 1989, p. 81, aunque adelante su ejecución a comienzos del siglo XVI, y lo relaciona con el que preside el retablo de la Capilla Dorada de la Catedral Nueva. Nada nuevo aporta J. ÁlVAREZ VILLAR, «Iglesias y Conventos», en Varios Autores, Salamanca ciudad europea de la cultura 2002. Salamanca, 2002, p. 244.

${ }^{39}$ M. GÓMEZ MORENO, Catálogo monumental..., p.
Pero quizás haya sido José Ángel Rivera de las Heras quien más argumentos ha proporcionado sobre el posible autor de estas imágenes, aunque como GómezMoreno también supone que debió pertenecer al retablo que anteriormente había en dicho templo ${ }^{40}$. Para este investigador no hay duda de que estamos ante unas imágenes salidas de las gubias del escultor de origen flamenco Gil de Ronza (Ronse $\mathrm{H}$. 1483-Zamora 1534). Se trata de un artista que desarrolló la mayor parte de su actividad en la ciudad de Zamora, donde consta afincado entre 1523 y 1534, lo que no obsta para pensar que su llegada a la ciudad castellana pudiera haberse producido algunos años antes, pudiendo incluso encontrarse entre los tallistas que trabajaban en los relieves de la sillería y puerta de acceso al claustro de la seo zamorana.

Ya dijimos en otro momento que su relación con Salamanca, y más concretamente con la Universidad, data del año 1509 , en el mes de diciembre recibe un pago de 100 reales de plata por la imagen de San Nicolás que había realizado ${ }^{41}$. Dado que por esos años la comisión del retablo está tratando la realización del calvario, no sería muy aventurado suponer que el encargo recayera sobre él, máxime teniendo en cuenta las similitudes estilísticas existentes entre el crucificado actualmente en el retablo de San Benito y otros atribuidos al imaginero flamenco, como el conocido como Cristo del Miserere que se conserva en la

220

40 J. A. RIVERA DE LAS HERAS, En torno al escultor Gil de Ronza. Zamora, 1998, pp. 101-102.

41 M. GÓMEZ-MORENO, «La capilla...», p. 327. Aunque Rivera de las Heras afirma que el destino de esa imagen debía ser el retablo de la capilla de San Jerónimo, ningún documento lo confirma. Cabe también la posibilidad de que fuera destinada a la capilla de esa misma advocación dependiente del Estudio, templo donde se enterraban los pobres del Hospital de Santo Tomás. 
iglesia de San Martín de la localidad salmantina de San Martín del Castañar ${ }^{42}$. No acabó ahí su vinculación a la ciudad del Tormes, ya que sus trabajos para la catedral están documentados entre los años 1524 y 1525, aunque existen discrepancias sobre dónde se centró, para unos en el hastial de poniente, para otros en la decoración de la Capilla de Todos los Santos ${ }^{43}$.

Estilísticamente el grupo responde a una sensibilidad habitual en el tardogótico castellano, importada a través de las obras $y$ artistas de origen flamenco que, en abundancia, llegaron a la Península en la segunda mitad del siglo XV y primeros años del $X V I$. Se trata de unas imágenes que destacan por su profunda emotividad, sin duda más acentuada con la policromía original. La anatomía del crucificado, expirado, re- produce un modelo habitual al de otros que se han vinculado a este maestro, como ya señaló el citado Rivera de las Heras. Por su parte María, en cuya túnica pueden adivinarse unos motivos en relieve que sugieren los brocados habituales en los tejidos contemporáneos, se ajusta al modelo de mater dolorosa tan caro a los artistas flamencos del XV, como lo demuestra la emoción contenida del rostro y el gesto de las manos.

No quisiera terminar sin dejar planteada una cuestión, y no es otra que la conveniencia, o no, de devolver estas figuras a su imagen primitiva, evitando de ese modo la condición de grisallas tridimensionales que hoy transmiten, y recuperando los valores expresivos que la policromía confería a la escultura de ese momento.

42 J. A. Rivera de LAS HeRAs, En torno al escultor..., p. 103.

43 J. A. RIVERA DE LAS HERAS, En torno al escultor..., defiende su participación en la decoración del imafronte, y añade también su intervención en la fachada de la iglesia del Convento de San Esteban. Por el contrario, se manifiestan a favor de su participación en la talla de las imágenes de la Capilla de Todos los Santos, entre otros: A. CASTRO SANTAMARÍA y J. C. BRASAS EGIDO, «La capilla dorada», en Las Edades del Hombre. El contrapunto y su morada, Salamanca, 1993, pp. 117122, y F. PEREDA, «Antonio de Malinas, un escultor de los Países Bajos en la España del Renacimiento», Archivo Español de Arte, 2004, pp. 139-157. 


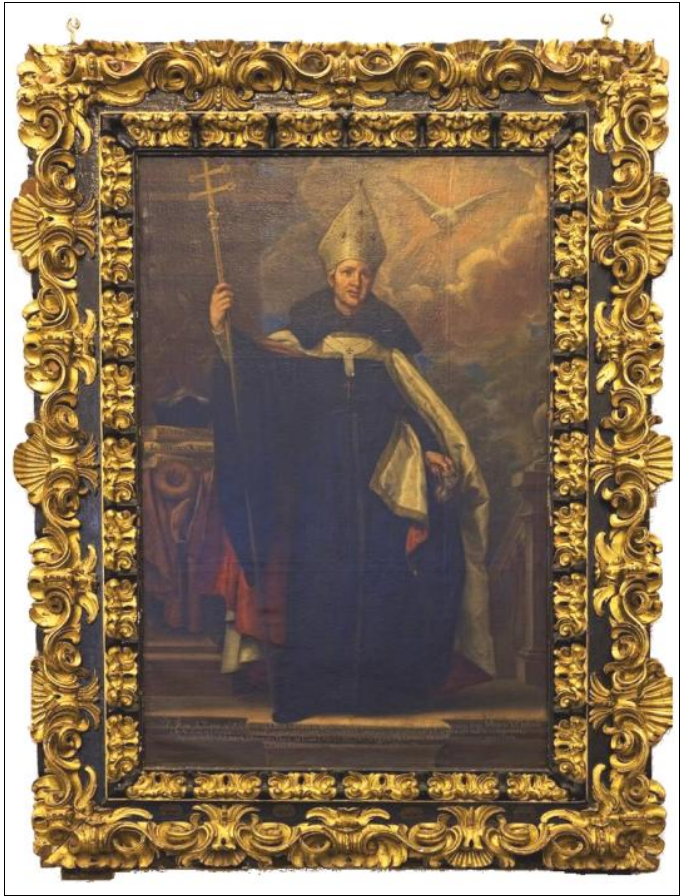

- Fig. 1a. Claudio Coello. Lienzo de Santo Tomás de Villanueva. Capilla de la Venerable Orden Tercera del Carmen. Salamanca.

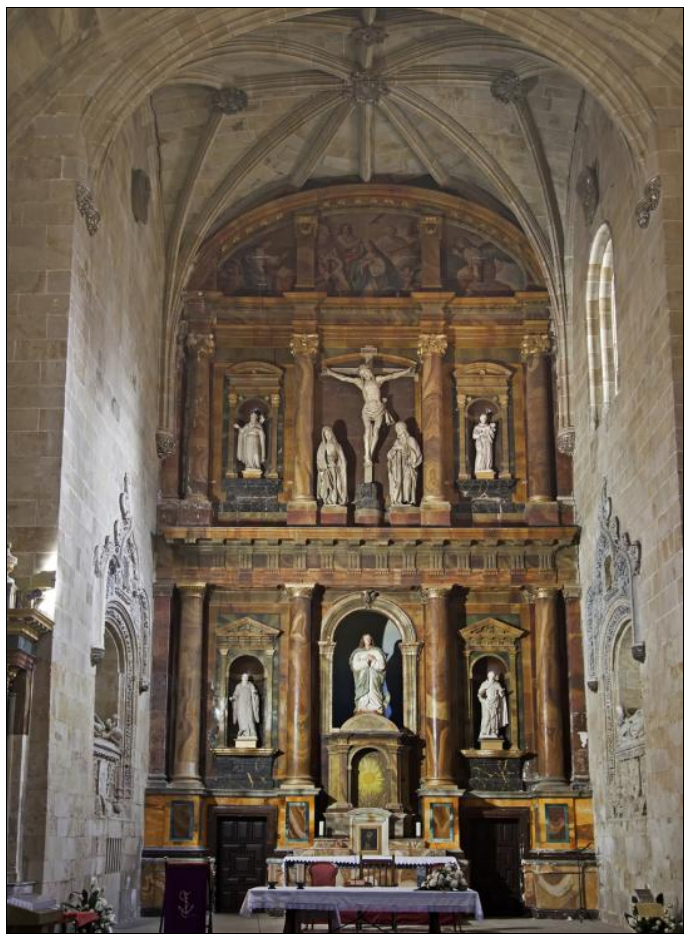

- Fig. 2. Retablo de la iglesia de San Benito. Salamanca.

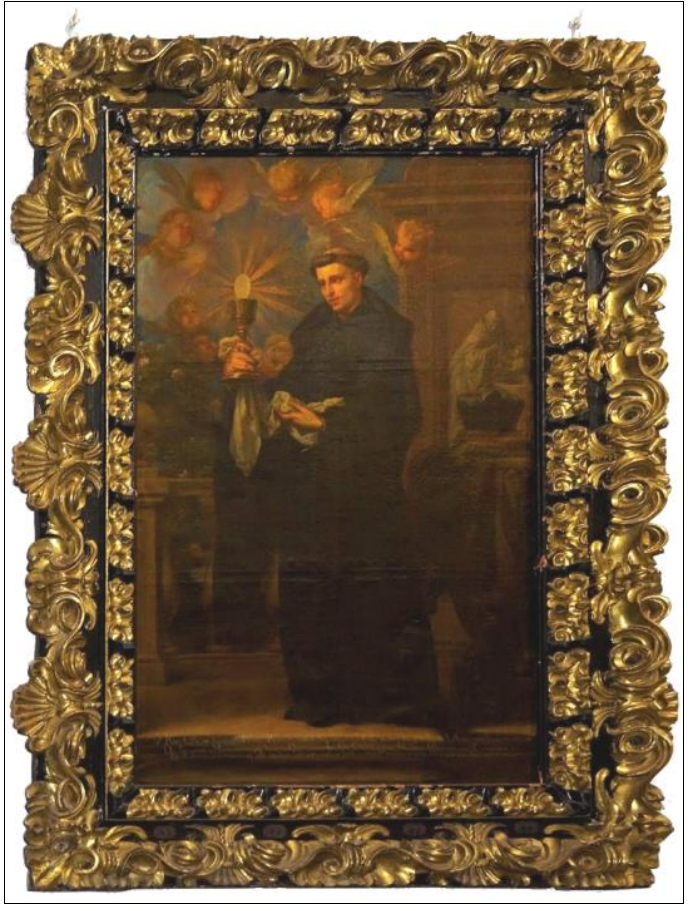

- Fig. 1b. Claudio Coello. Lienzo de San Juan de Sahagún. Capilla de la Venerable Orden Tercera del Carmen. Salamanca.

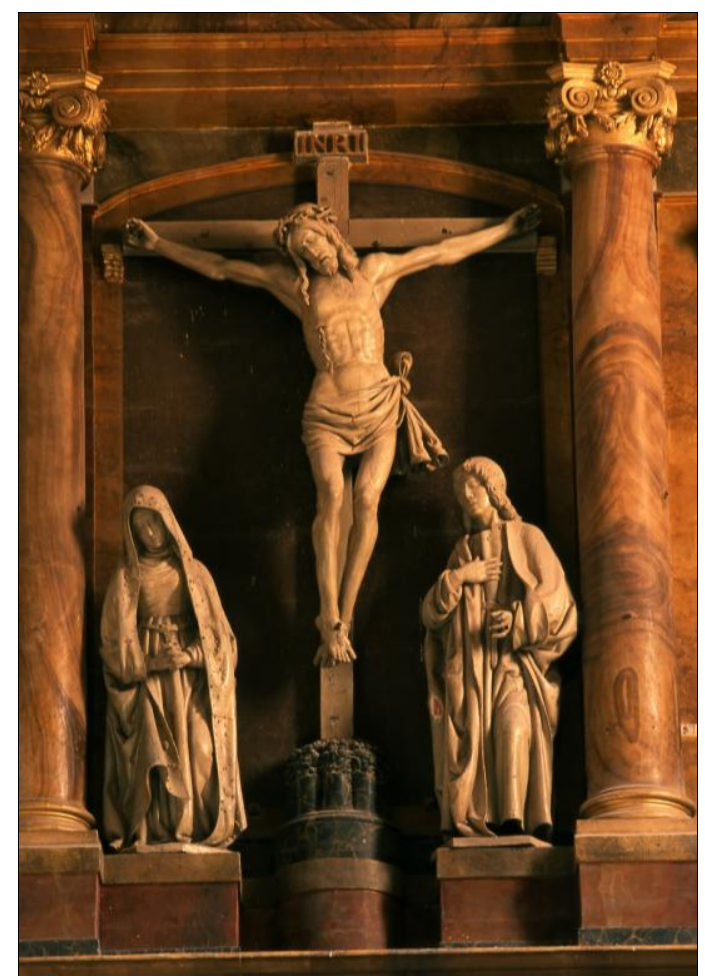

- Fig. 3. Calvario del retablo de la iglesia de San Benito. Salamanca. 